\title{
De la tarta de manzanas a la estética business-pop
}

\author{
Nuevos lenguajes para la sociedad de \\ la información
}

\section{Susana Finquelievich*}

\begin{abstract}
Resumen / De la tarta de manzanas a la estética business-pop
Desde una óptica que focaliza la revolución tecnológica como eje del cambio acelerado de las bases materiales de la sociedad, la autora sitúa los sistemas de red como un factor que acrecienta la complejidad de la interacción social emergentes del poder creativo de las lógicas propias de la red. Enfatiza sobre la circulación de flujos de información, que conforman un nuevo espacio de prácticas sociales, afectando el poder, las instituciones y los medios de comunicación. A partir de este esquema, la autora analiza el alcance de la tecnología como un factor no determinante de la sociedad. Focaliza a la revolución tecnológica en el orden metodológico y a éste, a su vez, en la determinación de factores exógenos -país, momento histórico, cultura- respecto de los resultados de su impacto. En un diagnóstico que define a la red como la forma virtual y simbólica por excelencia, el análisis enlaza el eje cartesiano con la cultura, los sujetos y las nuevas formas de producción de objetos culturales.
\end{abstract}

\section{Descriptores}

Ciberespacio / Comunicación multidireccional / Herramientas / Internet / Realidad virtual / Revolución tecnológica / Sistemas de red / Sociedad informacional / Tecnologías de la información

\section{Summary / From the apple pie to the estetic of the bussiness - pop}

From an optic that focuses the technological revolution as an axis of the material basis change of the society, the author places the net systems as a factor that increases the complexity of the social interaction, emerging from the creative power of the own net logic. It emphasizes on the circulation of the information flows, that forms a new room of the social practices, having an effect on the power, the institutions and the media. From this schema the author analyses the reach to the technology as a non determined factor of the society. She focuses the technologic revolution in a methodological manner and this last one, in the determination of external factors -country, historic moment, culture - with respect to the results of its own impact. In a diagnosis that defines the net as the virtual and symbolic form par excellence, the analysis links the Cartesian axis with the culture, the persons and the new forms of the production of the cultural objects.

\section{Resumo / Do pastel de maça à estética business-pop}

Desde uma óptica que focaliza a revolução tecnológica como eixo da mudança apressada das bases materiais da sociedade, o autor situa aos sistemas de Rede como um fator que acrescenta a complexidade da interação social emergentes do poder criativo das lógicas próprias da Rede. Enfatiza a circulação do fluxo de informação que conformam um espaço novo de práticas sociais, afetando o poder, as instituições e os meios de comunicação. A partir de este esquema, o autor analisa o alcance da tecnologia como um fator que não determina a sociedade. Focaliza à revolução tecnológica na ordem metodológica e este, a sua vez, na determinação de fatores exógenos - país, tempo histórico, cultura- a respeito dos resultados do seu impacto. Em um diagnóstico que define à Rede como a forma virtual e simbólica por excelência, analise tece o eixo cartesiano com a cultura, os sujeitos e as novas maneiras de produção de objetos culturais. 
Un nuevo paradigma tecno-social: La Sociedad Informacional> Deremate.com, Laborum.com, Elsitio.com... Desde los últimos meses de 1999 hasta mediados del 2000 , se ha producido una verdadera explosión de Internet en la sociedad argentina. Los www y los .com son ingredientes inevitables en la cotidianeidad, y no solamente en la pantalla de las computadoras: aparecen incesantemente en todos los medios de comunicación: afiches callejeros, señales de calles, programas televisivos y radiales, diarios, revistas. Una población creciente visita estos sitios y los usa para diferentes propósitos. Vivimos actualmente la transición de la sociedad industrial hacia la sociedad informacional. Las tecnologías de información y comunicación (TIC) permean todas las actividades sociales, desde el teletrabajo a las relaciones virtuales. Su rápida difusión plantea desafíos sin precedentes para los países latinoamericanos con respecto a su rol en la era de la información: la "ventana al mundo" representada por Internet se abre a un panorama de riesgos y oportunidades. Los programas gubernamentales se multiplican, surge el e-government, el comercio electrónico moviliza millones de dólares y las organizaciones comunitarias conforman redes virtuales. ¿Pueden transmitirse nuevas ideas con viejos lenguajes? ¿Qué nuevos códigos visuales y verbales están surgiendo? ¿Conforman éstos una nueva cultura, formas innovadoras de pensar y de hacer? Este artículo reflexiona sobre los ejes sociales de la sociedad informacional y plantea interrogantes con respecto a las necesidades en diseño y comunicación. Vale la pena detenerse para recordar las definiciones de la sociedad informacional. Castells, (1997) se refiere a sus orígenes de esta manera: "Una revolución tecnológica, centrada en las tecnologías de información, está reconformando, a paso acelerado, las bases materiales de la sociedad". El antiguo paradigma de producción, basado en inputs baratos de energía, es reemplazado por otro, basado predominantemente sobre inputs baratos de información, derivados de los avances de la tecnología microelectrónica y de telecomunicacio-nes. Castells analiza las principales características de este nuevo paradigma: la primera es la materia prima: tecnologías que actúan sobre la información, al contrario de las anteriores revoluciones tecnológicas, en las que la información actuaba sobre las tecnologías; la segunda se refiere a los efectos de estas tecnologías: dado que la información es una parte integral de las actividades humanas, todos los procesos de nuestra existencia individual y colectiva están conformados por el nuevo medio tecnológico. La tercera característica se basa en la lógica de red de cualquier sistema o conjunto de relaciones que use las tecnologías de información; la morfología de la red se adapta perfectamente a la creciente complejidad de interacción y a las impredecibles formas de desarrollo que emergen del poder creativo de dicha interacción. La cuarta se refiere a la flexibilidad que caracteriza este paradigma; no sólo los procesos son reversibles, sino que las organizaciones e instituciones pueden ser modificadas y alteradas mediante la redisposición de sus componentes. Se pueden revertir las reglas sin destruir la organización. Por último, la quinta característica de la revolución informacional es la creciente convergencia de tecnologías específicas en un sistema altamente integrado; La microelectrónica, las telecomunicaciones, la optoelectrónica y las computadoras conforman un sistema informacional.

Munida de estas propiedades, la sociedad de la información se construye en torno a redes de circulación de flujos: flujos de capital, de información, de tecnología, de imágenes, de interacción organizativa, sonidos y símbolos, que expresan los procesos que dominan la vida económica, política y simbólica. Se conforma un nuevo espacio de las prácticas sociales: el espacio de los flujos, la "organización material de las prácticas sociales en tiempo compartido que funcionan a través de los flujos" (Castells, M: 1997). El soporte material de las prácticas sociales dominantes son los elementos que sostienen los flujos y posibilitan su articulación en un tiempo simultáneo. Las estructuras dominantes, sostiene Castells, incluyen "los dispositivos de organizaciones e instituciones cuya lógica interna desempeña un papel estratégico para dar forma a las practicas sociales y la conciencia social de la sociedad en general". El poder ya no se concentra en las instituciones dominantes tradicionales (estado, empresas capitalistas, iglesias, medios de comunicación). El poder en la sociedad red, como afirma Manuel Castells(1997): "reside en los códigos de información y en las imágenes de representación en torno a los cuales las sociedades organizan sus instituciones y la gente construye sus vidas y decide su conducta. La sede de este poder es la mente de la gente". Subrayemos esto: el poder reside en los códigos de información y en las imágenes de representación. Es decir, en la información y la comunicación. 
A partir de la década de los ochenta, las nuevas tecnologías transformaron los medios de comunicación. Se extendió el uso de los aparatos de video y los walkman; los diarios se escriben, editan e imprimen a distancia, permitiendo ediciones simultáneas. Durante la década del noventa se desarrollan las tecnologías de televisión por cable: las fibras ópticas, la digitalización y la transmisión por satélite expandieron la transmisión.

En la segunda mitad de la década del noventa, se fusionaron los medios de comunicación de masas y la comunicación mediatizada por computadoras, formando un nuevo sistema electrónico de comunicación. El sistema multimedia integra diversos medios y se caracteriza por su potencial interactivo. Su uso se extiende a todos los ámbitos de la vida cotidiana: desde el hogar, el trabajo, la educación, la salud y el entretenimiento. Castells (1999) afirma que "quizá el rasgo más importante de los multimedia sea que captura dentro de sus dominios la mayor parte de las expresiones culturales en toda su diversidad". Se construye un nuevo entorno simbólico. "Hace de la virtualidad nuestra realidad", afirma Castells, quien define las características del sistema de comunicación que genera virtualidad real: "Es un sistema en el que la misma realidad (esto es, la existencia material/simbólica de la gente) es capturada por completo, sumergida de lleno en un escenario de imágenes virtuales, en el mundo de hacer creer, en el que las apariencias no están sólo en la pantalla a través de la cual se comunica la experiencia sino que se convierten en la experiencia". Estamos en los primeros pasos de una nueva cultura comunicacional.

\section{Tecnología y cultura}

La revolución de la información tecnológica, desde el punto de vista metodológico, es también un punto de partida apropiado para analizar las complejidades de la cultura en la sociedad de la información y en particular, de uno de sus máximos exponentes, la cultura de la transición entre los dos milenios. Como lo recuerda Manuel Castells, esta decisión metodológica no implica que las nuevas formas y procesos sociales emerjan como consecuencia del cambio tecnológico. La tecnología no determina a la sociedad. Tampoco significa que la sociedad avance siguiendo fielmente los meandros de las transformaciones tecnológicas. Son muchos los factores, incluyendo la inventiva e iniciativa individuales, el azar, las circunstancias económicas, políticas o geográficas, que intervienen en los procesos de los descubrimientos científicos, en los de innovación tecnológica y en los de su aplicación social. Los resultados y productos finales dependen de una compleja trama de interrelaciones.

Cuando en la década de los 70 emergió un nuevo paradigma tecnológico, organizado alrededor de la tecnología informática, sobre todo en los Estados Unidos, no fue causado por toda la sociedad norteamericana, sino por un segmento específico de esa sociedad, cuya interacción con la economía global y la geopolítica mundial, se materializó en nuevas maneras de producir, comunicar, aprender, enseñar, administrar y vivir.

El país, el momento histórico y la cultura donde se originó este proceso no son indiferentes a sus resultados. Como señala Castells, el hecho de que la construcción de este paradigma tuviera lugar en los Estados Unidos, y más precisamente en California y en los años 70, ha tenido probablemente fuertes consecuencias sobre las formas y la evolución de las nuevas tecnologías de información. Por ejemplo, a pesar del rol decisivo de la financiación y mercados de origen militar en el desarrollo de las primeras etapas de la industria electrónica, el florecimiento tecnológico que tuvo lugar a comienzos de los 70 puede relacionarse con la cultura de liberación, innovación, individualidad, imaginación e iniciativas de todo tipo que surgió de la cultura setentista en los campus americanos. Los militares y los Flower Children fueron los inesperados padres de la revolución tecnológica, los abuelos de la sociedad de la información. Esto no se sostiene en términos políticos sino con respecto a los valores sociales de ruptura con las pautas establecidas de conducta individual y social, tanto en la sociedad en general, como en los laboratorios tecnológicos y en el mundo empresario.

La cultura hippie influyó en la creación tecnológica. El énfasis en artefactos personalizados, en la interactividad, en el trabajo en red o networking, y la búsqueda incesante de nuevos medios tecnológicos, aún en circunstancias en que aparentemente no tendrían una salida inmediata en el mundo empresario, marcaban una clara discontinuidad con la tradición del mundo empresario de la época. La revolución de la tecnología informática, según Manuel Castells, difundió, conscientemente o no, el espíritu libertario que había florecido en los 60 en la cultura material de nuestras sociedades.

Tan pronto como estas tecnologías se difundieron y fueron apropiadas por países y culturas diferentes, por diversas organizaciones, 
y en respuesta a diferentes objetivos y utilidades, se desarrollaron todo tipo de aplicaciones y usos. A su vez éstos retroalimentaron la innovación tecnológica, acelerando su velocidad, ampliando el scope del cambio tecnológico y diversificando tanto las fuentes como sus productos. Se creó una relación biunívoca entre tecnología y demanda social, entre tecnología y cultura: si bien es cierto que la oferta tecnológica, el famoso "tirón tecnológico", determinó en parte la sociedad y las nuevas formas culturales, también lo es que la demanda fue condicionando la producción de tecnologías. Internet ilustra bien estos conceptos. Como se sabe, se originó en un modelo osado imaginado en 1960 por los "guerreros tecnológicos" del USA Defense Department Advanced Research Projects Agency (DARPA), para protegerse de los peligros soviéticos y de la destrucción de las comunicaciones americanas en caso de guerra nuclear. Era en cierta forma el equivalente tecnológico de las guerrillas: flexible, descentralizado. El producto fue una arquitectura de red que no puede ser controlada por ningún centro, y está compuesta por miles de redes autónomas de computadoras que poseen maneras innumerables de relacionarse, circunvalando las barreras electrónicas.

Actualmente Internet es un semillero de empresas, pero también un foro sobre derechos humanos; una biblioteca casi infinita, pero también una multiplicidad de comunidades virtuales. De producto de defensa militar, se ha vuelto polimórfico. Producto de la cultura setentista, contribuye a modelar la del fin del milenio. Como plantea Guy Sorman" "Internet se ha convertido en la parte más visible de la cibercultura, pero ésta no se reduce a Internet: también abarca la inteligencia artificial, la realidad virtual, las artes y los juegos interactivos (...). El término cibercultura (...) designa un universo a la vez técnico y espiritual, donde la computadora pasa a ser una prolongación de la personalidad humana, una especie de acelerador de nuestras capacidades psíquicas".

La influencia de las culturas "madres", la hippie y la tecnológica, sobre Internet, se hace evidente en los lenguajes usados para la comunicación, como veremos en el punto siguiente.

\section{La evolución de las imágenes: plazas, darkies y e-commerce}

Es interesante observar cómo el manejo de las imágenes ha ido evolucionando desde los comienzos de la difusión de internet hasta el presente, a medida que los comunicadores modificaron su actitud con respecto a esta tecnología y se insertaron en forma diversa en los distintos ámbitos de trabajo. Internet es, por definición, el reino de las metáforas, el mundo de los símbolos. Es, después de todo, el medio de desarrollo de la virtualidad, en cualquiera de sus formas posibles. Quizás convenga recordar que la realidad, tal como se la experimenta, siempre ha sido virtual, porque se la percibe a través de símbolos que enmarcan las prácticas con significados que escapan a las definiciones estrictamente semánticas. Es precisamente esta capacidad que poseen todas las formas de lenguaje, de codificar la ambigüedad y de abrirse a una multiplicidad de interpretaciones, lo que hace que las expresiones culturales difieran del razonamiento de la lógica matemática formal.

Manuel Castells afirma: "Es a través del carácter polisémico de nuestros discursos que se manifiesta la cualidad compleja y a veces contradictoria de los mensajes del cerebro humano. Este rango de variación cultural de los significados de los mensajes es lo que nos posibilita interactuar con los demás en una multiplicidad de dimensiones, algunas explícitas, otras implícitas. Por esto, cuando los críticos de los medios electrónicos argumentan que el nuevo espacio simbólico no representa la "realidad", están refiriéndose implícitamente a una noción absurdamente primitiva de experiencias reales no codificadas que nunca existieron. Todas las realidades se comunican a través de símbolos. Y en la comunicación humana, interactiva, independientemente del medio, todos los símbolos están en cierto modo desplazados en relación a su significado semántico. En cierto sentido, toda realidad es percibida virtualmente".

¿Cuándo puede decirse que un sistema de comunicación genera la virtualidad real? Cuando ese sistema captura la realidad (es decir, la existencia material/simbólica de las personas) y la sumerge en un encuadre virtual, en el cual las apariencias no son sólo imágenes o símbolos en la pantalla, a través de los cuales se comunica la experiencia, sino que devienen la experiencia misma. Pierre Levy, autor de "La technologie de l'intelligence", afirma: "Pero lo virtual es real. Como seres humanos nacemos con el lenguaje, luego vivimos el fin de la humanidad en el interior de mundos que son virtuales. No sólo el signo es virtualidad: la prueba es que podemos imaginar una posibilidad diversa a la realidad. 
Algunos piensan que la realidad virtual no es verdaderamente real, pero representa o evoca la realidad. Lo virtual (que según dichas opiniones debe ser parte del mapa pero no del territorio) en realidad actúa sobre la realidad. Por eso el mapa es el territorio, ya que es un operador del mismo", y añade: "No se puede razonar en términos de virtual y real de manera separada. Por consiguiente, no se necesita imaginar la cuestión en términos de sustitución, sino de complejidad, de imbricación, de redefinición, de apertura de nuevos espacios. La invención de la escritura ha producido enormes cambios y muchas cosas están captadas por este nuevo sistema de signos. La gente, sin embargo, no ha dejado de hablar"2.

El mundo virtual es infinito, y en él todo es posible, cualidades ambas que infunden temor, a la vez que euforia. Quizá por eso surgió, en los primeros tiempos de su difusión, la necesidad de refugiarse en metáforas visuales conocidas, familiares, seguras. Geocities ofrecía "terrenos" en "manzanas" de un "barrio" virtual, para que los usuarios construyeran allí sus web pages. Los cibernautas ansiosos de discutir determinados temas con otros navegantes de Internet acudían a una "plaza" diseñada como las plazas en las que jugábamos en nuestra infancia: nada faltaba, ni los canteros bordeados de prolijos cerquitos, ni las fuentes de agua, ni los bancos. Una web page era "el hogar en el ciberespacio". Las asociaciones comunitarias que se habían extendido a la Red ofrecían "comunidades virtuales", pequeños y acogedores "pueblos" diseñados con mayor o menor detalle, pero siempre usando imágenes familiares y reconocibles. Se podía hacer trámites en el "edificio de la Municipalidad", comprar en el "shopping" o más localmente, en la "plaza del mercado", circular por una "calle" libre de accidentes de tránsito y bordeada de los "hogares" de los "residentes" en la comunidad, hacia el "café", donde luego de chatear con amigos o desconocidos, se recalaba en la "biblioteca" para consultar algún libro o documento. Si Internet hubiera estado dotado de olores, se hubiera podido percibir el perfume de las tartas de manzana en las cocinas y de los sachets de lavanda en los placares. Los "espacios" eran acotados, diseñados conservadoramente, al estilo de los suburbios de clase media de América del Norte, a salvo de perturbadoras nociones del infinito.

Poco a poco, este manejo de las imágenes ha ido cambiando. Cibernautas y diseñadores aprendieron a usar el ciberespacio, a aprovechar sus múltiples posibilidades. Alrededor de 1998-
1999, se impuso la tendecia "darkie" en sitios de todo tipo, impulsada por la estética "tecno" del cine de ciencia-ficción, fundamentalmente por peliculas como "Matrix" o "Johny Mnemonic". El ciberespacio se pintó de negro, azul y plateado, pero el mundo de la oscuridad tuvo una vida corta. Las empresas virtuales comenzaron a florecer, con la consiguiente demanda de nuevos diseños para convertirse en competitivas. Con la explosión del e-commerce, el diseño adquirió una importancia fundamental: más de una empresa virtual plena de ideas originales y con buen respaldo financiero fracasó porque el diseño desacertado de su sitio no invitaba a los visitantes a quedarse y menos aún a explorarlo.

La cultura hippie, madre no reconocida de la revolución tecnológica, hizo sentir su influencia. El mundo empresario del ciberespacio usa actualmente un lenguaje y un diseño inimaginables en el ámbito empresario "real". Reinan las competencias de informalidad y creatividad, mientras el lenguaje verbal y visual se juveniliza, se vuelve casi adolescente. Sitios como Uyuyuy.com, Felizcumple.com, Mercadolibre.com, Netjuice.com, celebran la facilidad de comprar y consumir con diseños fáciles y colores primarios. Los nombres de las empresas se refieren directamente a los bienes y servicios que ofrecen: Casamiento.com, Deregalo.com, Laboris.net, Kids.com, Saberdefutbol.com. En la Expo Internet de junio de 2000, en Buenos Aires, los stands multicolores eran atendidos por adolescentes embutidos en mamelucos y pelucas flurescentes y reinaba una atmósfera de libertad y excitación cercana a los recitales de rock.

En otros ámbitos, el diseño se mantiene conservador. Los sitios de instituciones de gobierno nacionales, provinciales y locales se atienen a un diseño "oficial", poco aventurero, continuador de la estética gubernamental del mundo presencial. Los websites de los partidos políticos recuerdan los folletos partidarios y expresan los mismo que los dicursos de los diarios cotidianos. Evidentemente, el mundo político aún no ha aprendido los lenguajes de la Sociedad de la Información.

\section{La comunicación y el diseño en la Sociedad Informacional}

¿Qué requiere la Sociedad de la Información de los comunicadores y diseñadores? ¿Qué les ofrece? Por primera vez en historia, los profesionales del diseño y la comunicación poseen un canal de 
comunicación de multimedios poderoso, interactivo: Internet. Herramientas impensables hace una década para diseñar y discutir la comunicación bidireccional o mutidireccional de ideas visuales y espaciales con clientes, usuarios, funcionarios y ciudadanos, son ahora posibles. El hipertexto les da a los diseñadores la posibilidad poderosa de conectar trozos aislados de información, apoyando al creador individual tanto como a la creación grupal.

Dos tendencias en comunicaciones que aparecían en el Siglo XX están empezando a converger al principio del nuevo siglo. La primera es la concentración de medios de comunicación audiovisuales, notablemente la televisión, como el lugar de una acción predominante para la expresión cultural en la sociedad occidental. La segunda es la aparición de Internet. La convergencia se hace posible porque la información de todos los tipos puede digitalizarse en una corriente de unos y ceros, y puede trasladarse sin la necesidad a ser contenida en un objeto físico. Un libro es, después de todo, información guardada en el papel, una película, información guardada en un film, y un modelo arquitectónico, es información preservada en cartón y madera. Estas formas de registro de datos pueden guardarse y transmitirse a través de Internet alrededor del mundo.

Esta modalidad tiene consecuencias en el mundo del diseño: en la sociedad industrial, diseñadores y clientes rara vez trabajaban juntos. En la sociedad conectada, los clientes demandan crecientemente una participación en la planificación de una campaña y en el diseño audiovisual. La integración y la síntesis son las habilidades fundamentales en los diseñadores y comunicadores. Tomar trozos de información en Internet o en la "realidad", transformarlos, combinarlos, sintetizarlos en una realización coherente, y hacerlo ágil y rápidamente, con una comprensión cabal del entorno al que se destina, se vuelve una necesidad imperiosa del oficio. Los profesionales deben manejarse en juegos complejos de interrelaciones profesionales y asumir un rol de facilitador e integrador del conocimiento y las disciplinas que se requieran. La profesion también se des-localiza. "Equipos virtuales" es un término que está de moda, pero que no representa nada nuevo en el campo del diseño. Durante los últimos años, equipos de especialistas en diseño y comunicación se han armado, trabajado, disuelto y vuelto a formar con otros integrantes. Lo nuevo en la sociedad de la información es que estos equipos virtuales pueden liberarse de las localizaciones físicas, de las oficinas de ladrillos y hasta de la afiliación organizacional. La administración de estos equipos se vuelve, por lo tanto, más compleja que nunca antes.

¿Qué respuestas debe dar la enseñanza en Diseño y Comunicación a los nuevos requerimientos? Evidentemente, no se pueden abordar nuevas necesidades sociales y laborales sin transforma-ciones en las culturas organizacionales, sin cambios en las carreras tradicionales, y sobre todo, sin crear nuevas carreras, aptas para desarrollarse en la Sociedad de la información. Pero innovación no significa ni improvisación ni des-profesionalización. Posedora de interrogantes, aunque no de respuestas, dejo abierto el debate, que presiento apasionado y rico.

\section{Notas}

1 Sorman, Guy: "Un mundo dividido por la cibercultura" en La Nación, Notas, Viernes 26 de marzo, 1999.

2 Ver Finquelievich, Susana, 1998: "@mores virtu@les", en http://www.enredando.com

\section{Bibliografía}

Abramson, Jeffrey B., F. C. Artenton y G. R Orren (1988), The Electronic Commonwealth: The Impact of New Media Technologies on Democratic Politics, New York, Basic Books, Inc.

\section{Business Week}

Internet Communities, Special Report, Mayo 5, 1997.

Castells, Manuel

(1997), The Rise of the Network Society, New York, Blackwell.

Finquelievich, Susana, compiladora

(2000): " ¡Ciudadanos, a la Red!", Buenos Aires, Ed. La Crujía.

Finquelievich, Susana y Ester Schiavo, comp. (1998): La ciudad y sus TICs, Bunos Aires, Universidad de Quilmes.

Finquelievich, Susana

(1998), "@mores virtu@les", en http://www.enredando.com

\author{
Finquelievich, Susana, con la colaboración de \\ Jorge Karol y Graciela Kisilevski \\ (1996), ¿Ciberciudades? Informática y gestión \\ urbana, Instituto Gino Germani Oficina de Publicaciones del \\ Ciclo Básico Común, Universidad de Buenos Aires.
}

Finquelievich, Susana, Jorge Karol y Alicia Vidal (1992), Nuevas tecnologías en la ciudad. 
Información y comunicación en la cotidianeidad, Buenos Aires, Centro Editor de América Latina.

\section{Lyotard, Jean-François}

(1984), The Postmodern Condition, Manchester, Manchester University Press.

\section{Markley, Robert Ed.}

(1996), Virtual Realities and Their Discontents, Baltimore, The John Hopkins University Press.

\section{Mele, Christopher}

(1997), "Cyberspace and Disadvantaged Communities: The Internet as a Tool for Collective Action", en: Peter Kollock and Marc

Smith, Eds. Communities in Cyberspace,

Berkeley, University Of California Press.

\section{Michalski, Jerry}

(1995), "What is a virtual community? (After the media (lass)", New Perspectives Quarterly, Spring, Vol. 12, No.2.

\section{Reid, Elizabeth}

(1996), "Communication and Community on Internet Relay Chat: Constructing Communities", en: Peter Ludlow, ed.: High Noon on the Electronic Frontier, Cambridge, The MIT Press,

\section{Rheingold, Howard}

(1994), The virtual Community: Homesteading on the Electronic Frontier, Harper Perennial, Reading, Massachussets.

Solana, Anna: sensaciones@internet.sex, en: www.enredando.com, 1998.

Sorman, Guy

"Un mundo dividido por la cibercultura" en La Nación, Notas, Buenos Aires, Viernes 26 de marzo, 1999

Wellman, Barry, Janet Salaff, Dimitrova D.,

Garton L., Gulia M., Haythonthwaite C.,

(1996), "Computer networks as social networks: collaborative work, telework, and virtual community", in: Annual Review of Sociology, Annual 1996, Vol. 22, pp. 213.

\section{Wellman, Barry y M. Gulia}

(1996), "Net surfers don't ride alone: virtual communities as communities", en: Communities in Cyberspace, Ed. P. Kollock, M. Smith, Berkeley, Univ. California Press. 